Louisiana State University

LSU Digital Commons

Faculty Publications

Department of Biological Sciences

$1-1-1995$

\title{
The impact of DAP inservice training on the beliefs and practices of kindergarten teachers
}

\author{
Julia H. Haupt \\ Brigham Young University \\ Jean M. Larsen \\ Brigham Young University \\ Clyde C. Robinson \\ Brigham Young University \\ Craig H. Hart \\ Brigham Young University
}

Follow this and additional works at: https://digitalcommons.Isu.edu/biosci_pubs

\section{Recommended Citation}

Haupt, J., Larsen, J., Robinson, C., \& Hart, C. (1995). The impact of DAP inservice training on the beliefs and practices of kindergarten teachers. Journal of Early Childhood Teacher Education, 16 (2), 12-18. https://doi.org/10.1080/1090102950160204

This Article is brought to you for free and open access by the Department of Biological Sciences at LSU Digital Commons. It has been accepted for inclusion in Faculty Publications by an authorized administrator of LSU Digital Commons. For more information, please contact ir@lsu.edu. 
1995

\section{The Impact of DAP Inservice Training of the Beliefs and Practices of Kindergarten Teachers}

Julia H. Haupt

Jean M. Larsen

See next page for additional authors

Follow this and additional works at: https://scholarsarchive.byu.edu/facpub

Part of the Educational Sociology Commons

\section{Original Publication Citation}

Haupt, J.H., Larsen, J.M., Robinson, C.C., \& Hart, C.H. (1995). Impact of Developmentally Appropriate inservice training on the beliefs and practices of kindergarten teachers. Journal of Early Childhood Teacher Education, 16, 12-18.

\section{BYU ScholarsArchive Citation}

Haupt, Julia H.; Larsen, Jean M.; Robinson, Clyde C.; and Hart, Craig H., "The Impact of DAP Inservice Training of the Beliefs and Practices of Kindergarten Teachers" (1995). All Faculty Publications. 2924.

https://scholarsarchive.byu.edu/facpub/2924 
Authors

Julia H. Haupt, Jean M. Larsen, Clyde C. Robinson, and Craig H. Hart 


\title{
The Impact of DAP Inservice Training on the Beliefs and Practices of Kindergarten Teachers
}

\author{
Julia H. Haupt \\ Jean M. Larsen \\ Clyde C. Robinson \\ Craig $\mathrm{H}_{\text {. Hart }}$ \\ Brigham Young University - Provo, Utah
}

\section{Introduction}

As teacher training institutions have adopted the NAEYC standards for developmentally appropriate practices [hereinafter DAP] (Bredekamp, 1987) and have begun to routinely train pre-service teachers in these principles the need for student teaching experiences which reflect this orientation has become a priority for many teacher educators. However, locating developmentally appropriate placement settings, particularly when large numbers of student teachers are being trained simultaneously, may be difficult in some localities.

In many schools, pressure from administrators, parents and colleagues encourages the use of developmentally inappropriate practices [hereinafter DIP] in kindergarten, such as skill drilling and abstract paperand-pencil exercises (Burts et al., 1992; Elkind, 1986). In contrast, cooperative efforts between university ECE faculty and public school teachers and administrators promoting the use of developmentally appropriate practices has the potential to both enhance the student teaching practicum as well as improve the quality of early education experiences for young children (Burts et al., 1993).

While it might be hoped that a strong educational background in DAP would be sufficient to assist preservice teachers to be effective agents for change in their future schools and classrooms, anecdotal observation in our area has not shown this to be true. Indeed, while a sizeable percentage of kindergarten teachers in the local district completed their early childhood degrees at the university, many have succumbed to the rigors of expectations for a formal instructional approach in kindergarten. Furthermore, since the DAP standards and guidelines for appropriate curriculum and assessment for young children are of fairly recent publication, many longtime teachers in the local district who hold philosophies congruent with developmental principles have not been formally introduced to NAEYC and the standards for appropriate practice.
Thus, when the kindergarten grade level leader of the local school district approached university faculty with questions ${ }^{-}$about current trends in early childhood education. an avenue for inservice training on developmental practices was initiated. Although recent publications (Kessler \& Swadener, 1992; Mallory \& New, 1994) have challenged the DAP construct and criticized the philosophy as narrow and cuiturally insensitive, Hart et al., (1995) point out that thus far, critics of DAP haven't presented a detailed aiternative paradigm, nor provided research support for their views. Indeed, Hart's et. al, (1995) recent work indicates that social inequity is more pervasive in developmentally inappropriate preschool classrooms than in those that are developmentally appropriate. While questioning the DAP construct can ultimately lead to constructive debate which may further strengthen the construct, research evidence currently points to desirable outcomes for children who participate in DAP classrooms (Marcon, 1994; Charlesworth, Hart, Burts \& DeWolf, 1993).

In the present project, DAP was considered to offer the best theoretical and practical model for training teachers to work with young children. In addition, the advantage of providing inservice through a collaborative effort involving both the school district and the university became immediately apparent. As noted by Charlesworth, Burts and Hart (1994), inservice education can provide the vital link in providing DAP models for pre-service teachers. In this instance, the university would benefit from enhanced placements for pre-service students, while the local teachers would be able to benefit from the expertise and research being done at the university.

While seminar groupings and other avenues for promoting change are emerging in various locales [see Mangione \& Maniates (1993) and Espinosa (1992) for examples of these efforts], this study represents a formalized assessment of the changes that were made in the beliefs and practices of kindergarten teachers involved in a series of inservice seminars on DAP. In addition, it explores the impact of student teachers as facilitators of that process. 


\section{Method}

Kindergarten and primary grade teachers from one school district were informed of the intent of the seminars and invited to participate. In all, twenty-five teachers (19 kindergarten and 6 primary grade) participated in the inservice training sessions. Of those who attended the seminar, teachers demonstrating high interest in making immediate changes in instructional practices were utilized for student teacher placement.

\section{Training Seminars}

The teacher inservice series on DAP was developed dynamically as the seminars proceeded. An initial introduction on how children learn as a basis for developmental practices in kindergarten and the eariy grades was presented. The questions and concerns raised by the participants in implementing DAP in the classroom guided the choice of the remaining ten seminar discussion periods. These seminar discussions (which lasted $1 \frac{1}{2}$ hours each) focused on the following broad areas:

- A functional definition of developmentally appropriate practices with a comparison of developmental and psychometric educational philosophies;

- The role of the teacher as a facilitator rather than a disseminator and the development of appropriate learning plans for integrating the curriculum;

- The use of appropriate assessment to evaluate individual children's progress and program effectiveness;

- Techniques to aid in transitioning to more developmental classroom practices (including a panel discussion highlighting the experiences of several of the participants who currently had student teachers and were engaged in the change process); and

- The current research findings regarding the effects of appropriate and inappropriate practices.

Halfway through the series of seminars, student teachers in teams of two were placed with four kindergarten teachers who indicated a desire to initiate more experiential learning activities in their classrooms. The student teachers worked with their cooperating teachers to implement a variety of curriculum and program modifications.

\section{Teacher Questionnaire}

In order to measure the impact of the training seminars and the contribution of student teachers as change agents in the classroom, teacher beliefs and practices were assessed using the Teacher Questionnaire (Charlesworth, Hart, Burts \& Hernandez, 1991). Data were complete for 15 of the 19 kindergarten participants. Items on the Teacher Questionnaire represent several areas of kindergarten instruction as specified in the NAEYC guidelines (Bredekamp, 1987); namely. curriculum goals, teaching strategies, guidance of socioemotional development, language development and literacy, cognitive development, physical development, aesthetic development, motivation and assessment.

The two major sections of the Teacher Questionnaire are The Teachers' Beliefs Scale (TBS), which assesses teacher's attitudes and/or beliefs, and The Instructional Activities Scale (IAS), which measures the developmental appropriateness of classroom practice. Each of the 36 TBS items is a statement (ex., It is for children to work silently and alone on seatwork). The respondent rates each item on a five-point Likert scale from "not important at all" to "extremely important." The IAS is composed of 34 items. Each item describes an activity (ex., participates in dramatic play) to which the respondent rates the frequency of availability in his/her classroom along a five-point scale from "almost never" (less than monthly) to "very often" (daily).

Teachers were asked to rate their attitudes or beliefs and practices at the beginning of the year and at the conclusion of the seminar sessions. Thus, the questionnaire provided two sets of scores for each respondent (one reflecting teacher beliefs and practices prior to the training and one which reflected these at the end of the training). Since the scores represented the means of each participant's response on the Likert-scale items, the score range was 1-5. Previous administrations of the Teacher Questionnaire, which included classroom observations, successfully differentiated teachers with scores above 3 as having more DAP classrooms while those below 3 were judged to be DIP (Charlesworth, et al. 1993). From the two scores, a change score was calculated for each teacher (see Table 1).

A validation study of the Teacher Questionnaire (Charlesworth, et al., 1993) identified six reliable belief factors on the TBS: four appropriate (Appropriate Social; Appropriate Individualization; Appropriate Literacy Activities; Appropriate Integrated Curriculum) and two inappropriate factors (Inappropriate Activities and Materials; Inappropriate Structure). Items describing reacher practices within six factors found by Charlesworth, et al., (1993) were included for analysis with the present sample. Three of these factors described appropriate practices (Appropriate Activities; Creative Exploratory Learning; Appropriate Integrated Curriculum) and three described inappropriate practices (Inappropriate Literacy Activities; Inappropriate Learning; Inappropriate Management \& Guidance Techniques).

A series of paired $t$-tests between the means of the pre- and post-seminar responses for items on both the beliefs and practices sections of the Teacher Questionnaire were conducted. The pre- and post-seminar means along with the respective change scores and levels of ignificance are presented in Tables 2 and 3 . 
Haupt, Larsen, Robinson, Han

\section{Results}

Table 1 summarizes the overall means of each kindergarten teacher's preipost-seminar beliefs and practices on the Teacher Questionnaire. Generally, the data demonstrates an increase in developmentally appropriate beliefs for 14 of the 15 kindergarten teachers surveyed. In addition, the majority of the study sample (12 of the 15 kindergarten teachers) reported an increase in the developmental appropriateness of their classroom practices. The two teachers who evidenced the most substantial change in both their beliefs and practices (ID \#s 15 \& 7) had student teachers in their ciassrooms. While negligible and/or slightly negative change scores were reported by the other two teachers who had student teachers, it is important to note that in these instances, the pre-seminar scores already reflected strong developmental philosophy and classroom practice. Therefore. less change was actually possible in those cases.

\section{TABLE 1. Pre/Post means for individual teachers on the beliefs and practices components of the Teacher Questionnaire}

Teachers with Student Teachers

\begin{tabular}{|c|c|c|c|c|}
\hline & & & & \\
\hline & Pre & & & Post \\
\hline 15 & 3.38 & {$[1.43]$} & $=$ & 4.81 \\
\hline 7 & 2.81 & {$[1.42]$} & $=$ & 4.23 \\
\hline 1 & 4.04 & {$[0.00]$} & $=$ & 4.04 \\
\hline 1 & 4.46 & {$[0.12]$} & $=$ & $\underline{4.58}$ \\
\hline & 3.67 & & & 4.42 \\
\hline
\end{tabular}

Teachers without Student Teachers

\begin{tabular}{rrlll}
\multicolumn{5}{c}{ Beliefs } \\
\\
\cline { 2 - 5 } 14 & 3.35 & {$[0.77]$} & $=$ & Post \\
8 & 3.08 & {$[1.33]$} & $=$ & 4.12 \\
4 & 3.51 & {$[0.72]$} & $=$ & 4.41 \\
5 & 3.19 & {$[1.32]$} & $=$ & 4.23 \\
9 & 3.09 & {$[1.12]$} & $=$ & 4.51 \\
11 & 3.42 & {$[0.65]$} & $=$ & 4.17 \\
6 & 3.56 & {$[0.52]$} & $=$ & 4.08 \\
10 & 4.46 & {$[0.46]$} & $=$ & 4.92 \\
12 & 3.85 & {$[0.31]$} & $=$ & 4.16 \\
2 & 4.51 & {$[0.22]$} & $=$ & 4.73 \\
3 & 3.96 & {$[0.46]$} & $=$ & 4.42 \\
& 3.63 & & & 4.36
\end{tabular}

In the paired t-tests on individual items of the Teacher Questionnaire which assessed teacher beliefs (see Table 2), high degrees of significance appeared on all but five of the items. It should be noted that all but three preseminar means were rated above a 3.0 and therefore considered developmentally appropriate. These three items significantly increased from pre-seminar to postseminar. Items that were not significant were scattered across the six factors, indicating that beliefs were influenced to some degree in each of the six areas. In contrast, as shown in Table 3 which reports changes in teacher practice. only eight of the items were found to be statistically significañit. While some increases in the

\begin{tabular}{|c|c|c|c|}
\hline \multirow[b]{2}{*}{ Pre } & \multicolumn{2}{|c|}{ Practices } & \multirow{2}{*}{ Post } \\
\hline & & & \\
\hline 3.19 & {$[1.62]$} & $=$ & 4.81 \\
\hline 3.48 & {$[1.26]$} & $=$ & 4.74 \\
\hline 4.33 & {$[-.04]$} & $=$ & 4.29 \\
\hline 4.17 & {$[0.04]$} & $=$ & 4.21 \\
\hline 3.79 & & & 4. \\
\hline
\end{tabular}

\begin{tabular}{llll} 
& \multicolumn{2}{c}{ Practices } & \\
Pre & & & Post \\
\hline 3.14 & {$[0.78]$} & $=$ & 3.92 \\
3.33 & {$[0.71]$} & $=$ & 4.04 \\
2.96 & {$[0.71]$} & $=$ & 3.67 \\
3.25 & {$[0.63]$} & $=$ & 3.88 \\
3.21 & {$[0.38]$} & $=$ & 3.59 \\
3.13 & {$[0.33]$} & $=$ & 3.46 \\
3.11 & {$[0.30]$} & $=$ & 3.41 \\
3.71 & {$[0.25]$} & $=$ & 3.96 \\
3.54 & {$[0.25]$} & $=$ & 3.79 \\
4.04 & {$[0.00]$} & $=$ & 4.04 \\
3.63 & {$[-.08]$} & $=$ & 3.55 \\
\hline 3.37 & & & 3.76
\end{tabular}

appropriateness of classroom practices (i.e., in the areas of Appropriate Activities, Creative Exploratory Leaming and Appropriate Integrated Curriculum) were reported, the three factors describing inappropriate practices (i.e., Inappropriate Literacy Activities, Inappropriate Learning and Inappropriate Management and Guidance Techniques) for the most were not significantly affected. Again, with few exceptions, the items were rated above a 3.0 prior to seminar instruction. As with the belief items, substantial increase was reflected in the post-seminar means. However, there were two inappropriate leaming items which indicated post-seminar means below 3.0. 
Table 2. T-test results between pre/post means of belief items on the Teacher Questionnaire

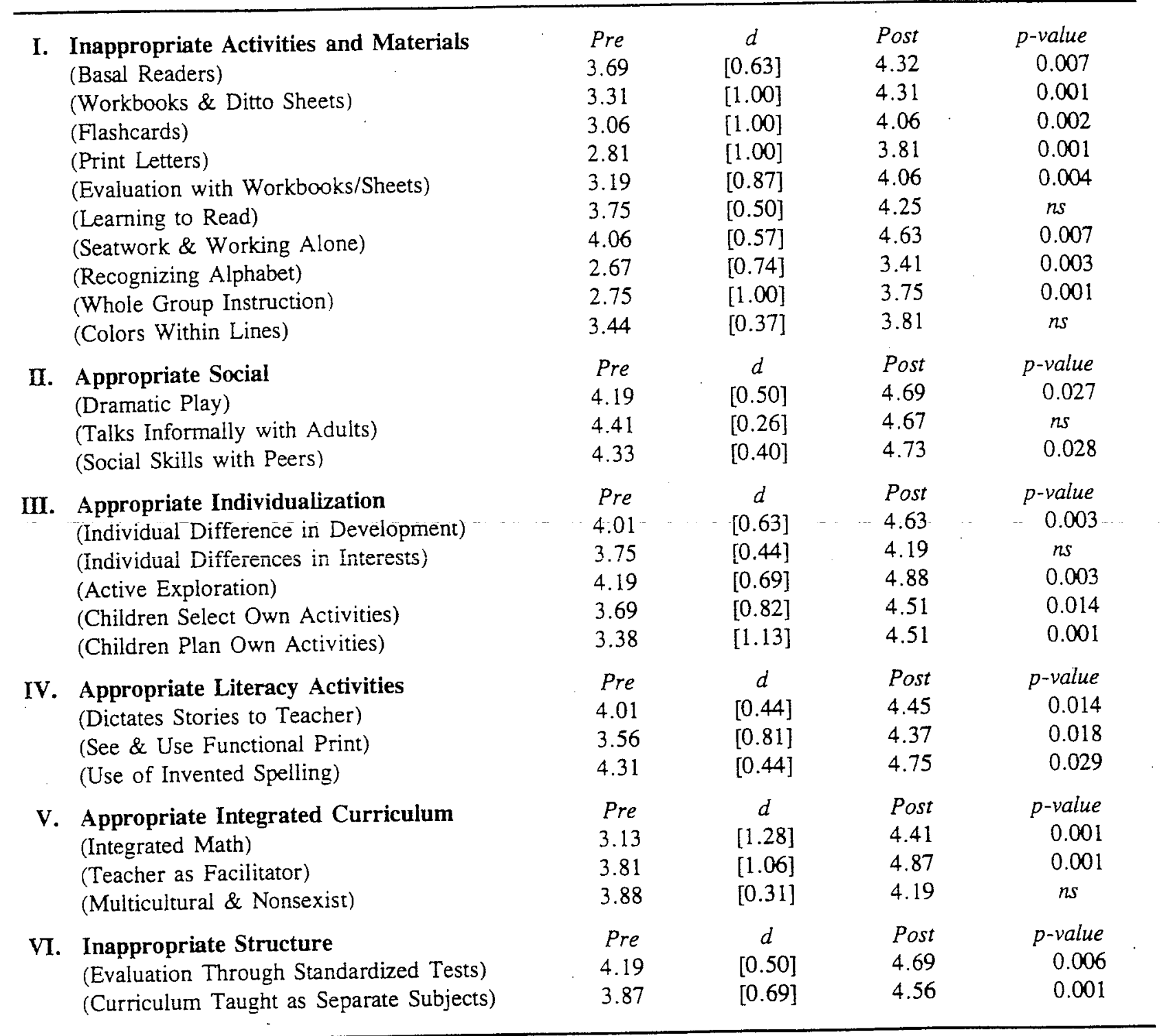

\section{Discussion}

Several interesting insights into the effectiveness of DAP inservice training for kindergarten teachers emerged in this study. First, it appears that DAP inservice can positively impact the beliefs and practices of teachers who are already sympathetic to developmental philosophy. As can be seen by a careful perusual of the pre-seminar scores for the participants, nearly all reported relatively high DAP scores ( 3.0 and above) in both beliefs and practices prior to the training. Although the invitation to be involved in the seminar series was sent to all kindergarten teachers in the district, it appears that those who readily accepted the opportunity were those who already had an interest in DAP and were more motivated to implement developmentally appropriate practices.
Second, the most dramatic changes were evident with two of the teachers who had student teachers in their classrooms. While the other two cooperating teachers showed very small leveis of change, their pre-seminar scores were already high (over 4.0 ) producing a possible ceiling effect. Certainly, additional investigation and replication of the impact of student teachers on cooperating teachers' beliefs and practices is warranted, since the number of teachers who had student teachers in their classroom was so small. However, the results suggest the potential for pre-service teachers in the classroom to facilitate more developmentally appropriate beliefs and practices for teachers involved in inservice training themselves. 
Table 3. T-test results between pre/post means of practice items on the Teacher Questionnaire

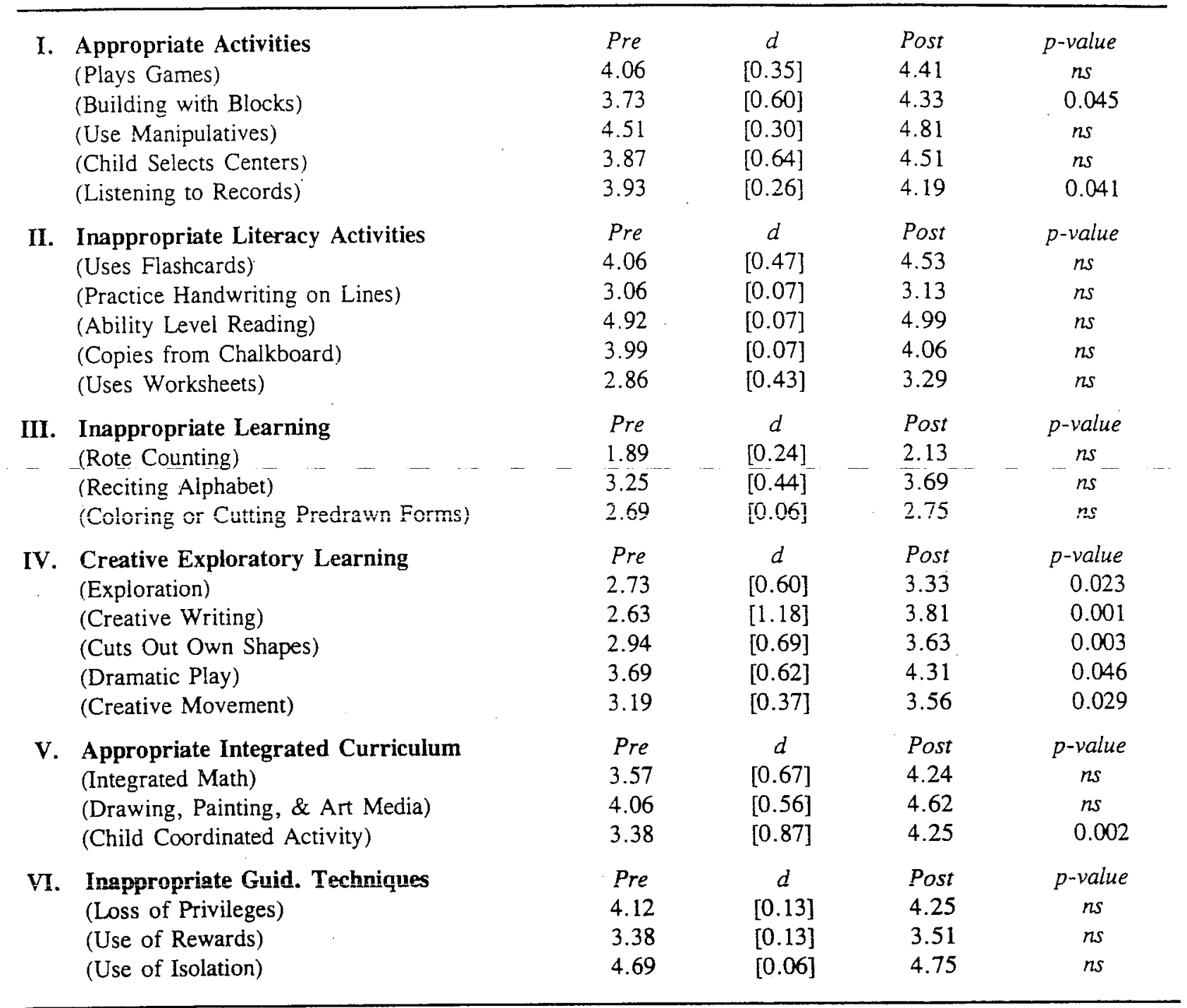

Particularly where both pre-service teachers as weil as cooperating teachers are being trained simultaneously in the principles of DAP, a partnership can emerge. The benefit of this partnership for the pre-service student is that the classroom setting becomes a more flexible environment in which the implementation of DAP principles becomes possible. In turn, cooperating teachers benefit by having access to informal consulting by both the students and their college supervisor, both of whom are aware of the particular needs and constraints of that classroom.

Third, as shown through a comparison of Tables 2 and 3 , beliefs were strongly affected by participation in the inservice seminars. Both the actual number of changes made as well as the high degree of significance associated with these changes is encouraging. It is worthy of note that the three belief items that could be considered DIP (below 3) prior to the training (i.e., printing letters, recognizing the alphabet and whole group instruction) improved significantly ( $p=.0003$ or less). Issues regarding appropriate practices on teaching the alphabetic principle in a print-rich classroom and in context (see Reutzel, 1992), as well as the value of small group instruction were discussed often in the course of the seminar. It is interesting to note that the means on these particular items moved into the range of DAP. Indeed, all beliefs were at the level of 3.4 or higher at the end of the seminar series.

The reported change in developmentally appropriate classroom practices was much more modest by comparison, as can be seen in Table 3. It is hoped that changes in beliefs will precipitate change in classroom practices, but these changes in practice may be much slower to emerge than changes in belief. Also, since the 
inservice instruction was spread over the course of a year's time, some teachers may have felt it unwise to make changes in routine and procedure with the children currently in their classrooms.

Table 3 indicates that the changes in practices that were significant emerged particularly in the area of 'Creative Expoloratory Learning. It appears that teachers were more willing to allow exploration, creative writing, dramatic play, creative movement and creative art in their classrooms as a result of participation. In addition, they provided more block play and listening to records. Finally, they demonstrated a willingness to allow the child more input and choice in classroom activities. Yet, as indicated earlier, inappropriate practices were not readily discontinued. Teachers seemed to continue the inappropriate practice of rote counting and coloring or cutting pre-drawn forms. It may be that providing additional developmentally appropriate activities in the classroom is an easier modification to make than discarding inappiopriate practices such as rote counting and/or the use of pre-drawn forms. It must be noted as well, however, that these two were the only practice items with post-seminar mean ratings low enough to be considered DIP.

Finally, since all areas of beliefs were significantly affected, while only a few areas of practice were significantly influenced, it appears that the teachers' involvement in the seminar series assisted them better in a broad philosophical sense, but selectively in their actual practices, similar to earlier studies (Charlesworth, Hart, Burts, \& DeWolf, 1993). Some of this may also be due to the way in which the seminars were conducted. Most of the instruction centered around philosophical issues. While practical examples were given. workshops that presented a variety of activities for ready implementation were not afforded.

As pointed out by Davis and Goffin (1994), allowing sufficient time for change is also important. Each teacher needs the freedom to determine those changes that are most relevant and necessary in their classroom situation. In addition. a continuing support system, including colleagues and university personnel, can continue to facilitate changes in practice over time. More than half of the kindergarten teachers initially involved in the seminars decided to form a support group for the following school year. Though less formal, these meetings have received the continued support and consultation of university faculty. Not surprisingly, most of these sessions have related to the issue of implementing developmental curriculum. As reported in a large scale project in the District of Columbia Public Schools (Sykes, 1994), follow-up support has become a critical component in lasting change (Wood, 1994).

In conclusion. the results of this study confirm that
DAP inservice training of kindergarten teachers can result in significant changes in the beliefs and practices of teachers who already have leanings toward developmental practices. Overall, the seminar series was regarded positively and led to changes in the classrooms. The initial objective of developing a cadre of classrooms and cooperating teachers who were better models of developmental practices was considered successful.

It was also rewarding from the standpoint of university personnel to formally introduce these teachers to NAEYC and the standards of developmentally appropriate practice (Bredekamp, 1987). The opportunity to develop a shared understanding of DAP concepts eases communication as college supervisors make suggestions to the pre-service teachers who are student teaching. The involvement of university faculty in the follow-up support meetings maintains the channel for open and supportive communication.

While the planning and presentation of the DAP seminar required an investment of time and energy by faculty, the commitment of university resources proved to be worth the effort. Not only did it encourage changes in the beliefs and practices of classroom teachers in the field, but it enhanced the student teaching practicum experience as well. In conclusion, this cooperative inservice venture is considered to have created a climate favorable for changes in classrooms that may ultimately benefit all involved - classroom teachers, children and teachers-in-training.

\section{References}

Bredekamp, S. (Ed). (1987). Developmentally appropriate practice in programs serving children from birth through age 8 (exp. ed). Washington, D.C.: National Association for the Education of Young Children.

Burts, D.C., Campbell, J., Hart, C.H. , Charlesworth, R., DeWolf, D.M., \& Fleege, P.O. (1992). A comparison of principals' beliefs with kindergarten teachers' beliefs and practices. Manuscript submitted for publication.

Burts, D.C., Hart, C.H., Charlesworth, R., DeWolf. D.M., Ray, J., Manuel, K., \& Fleege, P.O. (1993). Developmental appropriateness of kindergarten programs and academic outcomes in first grade. Joumal of Research in Childhood Education, 8(1), 23-31.

Charlesworth. R., Burts, D.C., \& Hart, C.H. (1994). The effectiveness of developmentally appropriate compared with developmentally inappropriate practices: Implications for teacher preparation. Journal of Early Childhood Teacher Education, 15(1), 8-12.

Charlesworth. R., Hart, C.H., Burts, D.C., DeWolf, M. (1993). The LSU studies: Building a research base for developmentally appropriate practice. In $S$. Reifel (Ed.), Advances in early education and day care. Vol. 5: Perspectives in developmentally appropriate practice (pp. 3-28). Greenwich. CT: JAI Press Inc. 
Charlesworth, R., Hart, C.H., Burts, D. C., \& Hernandez, S. (1991). Kindergarten teachers' beliefs and practices. Early Child Development and Care, 70, 17-35.

Charies worth, R., Hart, C.H., Burts, D. C., Thomasson, R.H., Mosley, J., \& Fleege, P.O. (1993). Measuring the developmental appropriateness of kindergarten teachers' beliefs and practices. Early Childhood Research Quarterly, 8, 255-276.

Davis, M.D. \& Goffin, S.G. (1994). Program improvement. in early childhood education: Facilitating the change process. Joumal of Early Childhood Teacher Education, 15(1), 3-7.

Elkind, D. (1986). Formal education and early childhood education: An essential difference. Phi Delta Kappan, 67 . 631-636.

Espinosa, L. (1992). The process of change: The Redwood City story. In S. Bredekamp \& T. Rosegrant (Eds.), Reaching Potentials: Appropriate curriculum and assessment for young children (pp. 159-166). Washington DC: National Association for the Education of Young Children.

Hart, C.H., Charlesworth, R., Durland, M.A., Burts, D.C., DeWólf, Mi., \& Fleege, P.O. (in press). Developmentally appropriate practices in preschool classrooms: Further support for SES and gender equity. Eariy Childhood Research Quarterly.
Kessler, S., \& Swadener, B.B. (1992). Reconceptualizing the early childhood curriculum: Beginning the dialogue. New York: Teachers College Press.

Mallory, B.C., \& New, R.S. (1994). Diversity and developmentally appropriate practices. New York: Teachers College Press.

Manigone. P.L. \& Maniates, H. (1993). Training teachers to implement developmentally appropriate practice. In S. Reifel (Ed.), Advances in early education and day care, Vol. 5: Perspectives in developmentally appropriate practice (pp. 145-166). Greenwich, CT: JAI Press Inc.

Marcon, R.A. (1994). Doing the right thing for children: Linking research and policy reform in the District of Columbia Public Schools. Young Children, 50(1), 8-20.

Reutzel, D.R. (1992). Breaking the letter-a-week tradition: Conveying the alphabetic principle to young children. Childhood Education, 69(1), 20-23.

Sykes, M. (1994). Creating a climate for change in a major urban school system. Young Children, 50(1), 4-7.

Wood, C. (i cosu). Responsive teaching: Creating partnerships for systemic change. Young Children, 50(1), 21-28. 
